\title{
Penentuan Orientasi dan Translasi Gerakan UAV menggunakan Data Fusion berbasis Kalman Filter
}

\author{
Freddy Kurniawan ${ }^{1 *}$, Muh. Ridlo Erdata Nasution ${ }^{2)}$, Okto Dinaryanto ${ }^{3)}$, Lasmadi ${ }^{1)}$ \\ 1) Teknik Elektro, Institut Teknologi Dirgantara Adisutjipto \\ 2) Teknik Dirgantara, Institut Teknologi Dirgantara Adisutjipto \\ 3) Teknik Mesin, Institut Teknologi Dirgantara Adisutjipto \\ * email: freddykurniawan@itda.ac.id
}

\begin{abstract}
Navigation system is essential in estimating the orientation and translation motion of UAV. The system can utilize data from several sensors and devices, e.g. MIMU and GPS. The orientation of $U A V$ can be precisely calculated by means of data from accelerometer and magnetometer when both sensors are in static state. Meanwhile, under dynamic conditions, the orientation can be more precisely predicted through the use of gyroscope sensor data. In order to attain a robust navigation system, a data fusion based on Kalman filter is built to estimate the orientation from the accelerometer, gyroscope, and magnetometer sensors. Moreover, for sake of achieving high accuracy, the filter will further correct the orientation by giving a higher weight to the data from accelerometer and magnetometer sensors when the UAV is in static condition. In the case of its position, the UAV position will be estimated by performing data fusion of MIMU and GPS data. Based on the experiments, it could be showed that data fusion based on Kalman filter provided more accurate results of orientation and position of UAV. The result of orientation based on gyroscope sensor data has an average error of $18.12^{\circ}$, while those obtained by accelerometer and magnetometer sensors data is $1.3^{\circ}$. Furthermore, by using the data fusion based on Kalman filter, the error of orientation predicted by combining data from accelerometer, magnetometer, and gyroscope will decrease to $0.87^{\circ}$.
\end{abstract}

Keywords - accelerometer, data fusion, gyroscope, Kalman filter, magnetometer, unmanned aircraft vehicle.

\section{Pendahuluan}

UAV (Unmanned Aircraft Vehicle) jenis quadrotor merupakan salah satu jenis pesawat tanpa awak yang banyak dikembangkan. Jenis pesawat ini banyak digunakan baik di kalangan militer maupun sipil karena kemudahannya dalam melakukan take-off dan landing di tempat dengan luas sangat terbatas [1]. UAV ini dapat menggunakan sistem kendali jauh (remote) atau autonomous. Penelitian tentang UAV ini telah berkembang dari modelling and control hingga navigasi [2].

Salah satu hal yang esensial bagi UAV adalah sistem navigasi. Dengan navigasi, UAV dapat menjelajah dengan benar [3]. Salah satu metode navigasi yang banyak digunakan adalah menggunakan satelit GPS (Global Positioning System). Namun metode ini memiliki beberapa kelemahan, di antaranya pada daerah yang kurang terbuka. Kurangnya jumlah satelit yang mencakup suatu daerah dapat menyebabkan sistem navigasi terganggu. Bahkan jika digunakan di dalam ruangan, sistem navigasi berbasis satelit ini dapat memberikan kesalahan yang besar. Keakuratan navigasi berbasis satelit juga dapat terganggu dengan adanya gangguan ionosfer [4] dan multipath effect [5].

Untuk mengatasi kelemahan navigasi berbasis satelit, dapat digunakan metode navigasi lain. Di antara beberapa metode navigasi yang ada, navigasi berbasis sensor IMU (Inertial Measurement Unit) dan MIMU (Magneto-IMU) merupakan navigasi yang banyak digunakan

Manuscript submitted 15 January 2021; revised 7 July 2021; accepted 8 July 2021.

Published 9 July 2021; http://dx.doi.org/10.28989/avitec.v3i2.890 
[6-7]. Sensor tersebut banyak digunakan untuk menentukan orientasi dan translasi pergerakan pesawat, roket dan benda-benda lain [8].

Namun data keluaran sensor IMU ini mempunyai beberapa kelemahan, di antaranya adalah harus diketahuinya lokasi inisial dan besarnya derau pengukuran. Hal ini menyebabkan galat navigasi akan semakin besar seiring bertambahnya waktu [9]. Berbagai penelitian telah dilakukan untuk mengurangi efek derau tersebut, di antaranya adalah menggunakan Kalman filter. Namun hasilnya belum memuaskan terutama untuk lintasan yang kompleks [2].

Pada penelitian ini dikembangkan metode navigasi dengan melakukan data fusion dari sensor akselerometer, giroskop, magnetometer dan GPS menggunakan Kalman filter. Metode navigasi ini cukup dapat diandalkan karena data sensor akselerometer, giroskop, magnetometer selalu tersedia dan tidak terpengaruh oleh berbagai faktor, misalnya waktu dan cuaca [10]. Sementara itu, data GPS bersifat global dan dapat digunakan untuk penentuan lokasi secara cukup akurat. Dengan data fusion berbasis Kalman filter ini didapat data sudut orientasi (arah) dan translasi (perpindahan) UAV dengan lebih tepat.

\section{Metode Penelitian}

\subsection{Data Fusion berbasis Kalman Filter dengan Kovarian Derau Pengukuran Dinamis}

Kalman filter merupakan salah satu algoritma yang dapat digunakan untuk melakukan estimasi suatu kondisi (state) dari sebuah kondisi awal. Filter digital ini dapat melakukan penggabungan data (data fusion) dari beberapa sumber. Lebih lanjut lagi, filter ini juga sekaligus mampu mengurangi derau data yang diestimasi, sehingga sekaligus berfungsi sebagai filter digital.

Secara umum, Kalman Filter mempunyai dua proses utama, yaitu prediksi dan koreksi. Proses prediksi mempunyai terdapat dua tahapan yaitu prediksi state dan prediksi kovarian galat. Sementara itu, proses koreksi terdiri dari tiga tahapan, yaitu: menghitung Kalman gain, update nilai prediksi dengan nilai pengukuran $\mathrm{Z}_{\mathrm{k}}$, dan update kovarian galat. Proses ini dilakukan secara terus menerus sehingga mengalami pengulangan sebagaimana Gambar 1.

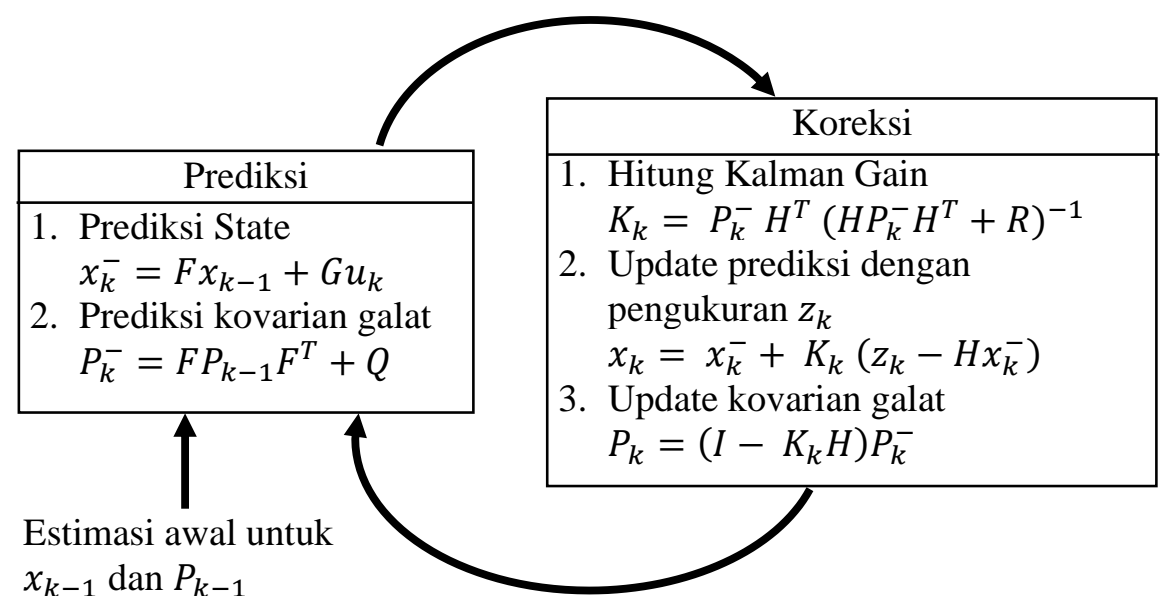

Gambar 1. Proses di Kalman Filter

Terdapat beberapa matriks penting pada Kalman filter. $F$ merupakan matriks transisi yang mengonversi state sebelumnya ke state saat ini, $G$ merupakan matriks transisi masukan yang mengompensasi masukan ke state saat ini, sedangkan $Q$ adalah matriks kovarian derau proses. Pemilihan nilai matriks $P, Q$, dan matriks kovarian derau pengukuran $R$ dapat mempengaruhi kinerja Kalman filter. Pemilihan nilai $P$ dan state inisial mempengaruhi konvergen awal filter ini, sehingga mempengaruhi juga seberapa lama filter ini siap untuk 
digunakan secara real time. Namun dalam banyak kasus, pengaruh ini tidak signifikan, sehingga untuk memudahkan perhitungan, $\mathrm{P}$ diisi dengan matriks identitas. Sementara itu, matriks $\mathrm{Q}$ dan $\mathrm{R}$ mempengaruhi pembobotan filter ini terhadap vektor prediksi state $x_{k}^{-}$dan nilai hasil pengukuran $z_{k}$. Perbandingan keduanya dapat dilihat dari nilai Kalman gain. Semakin tinggi Kalman gain, maka semakin tinggi pula bobot nilai hasil pengukuran [11].

Penggunaan nilai $Q$ yang besar mengindikasikan banyaknya derau pada proses propagasi. Dalam kondisi ini, Kalman filter akan memberikan bobot yang kecil kepada proses propagasi dan memberikan bobot yang besar pada nilai pengukuran, sehingga prediksi state $x_{k}^{-}$ akan banyak dikoreksi dengan hasil pengukuran keluaran $z_{k}$. Sementara itu, penggunaan nilai $\mathrm{R}$ yang besar mengindikasikan banyaknya derau pada nilai pengukuran. Hal ini menjadikan Kalman filter memberikan bobot yang lebih besar pada hasil propagasi dan bobot yang kecil pada nilai pengukuran, sehingga prediksi state $x_{k}^{-}$tidak akan banyak dikoreksi oleh hasil pengukuran keluaran $z_{k}$. Nilai Q dan R dapat diubah-ubah untuk menentukan pembobotan atas nilai keluaran beberapa sensor dalam proses penggabungan data sensor atau data fusion sebagaimana Gambar 2. Meski demikian, kebanyakan peneliti memilih adanya perubahan nilai $\mathrm{R}$ daripada $\mathrm{Q}$, karena pengubahan nilai $\mathrm{Q}$ dapat mengakibatkan adanya overshoot pada nilai Kalman gain [12-13].

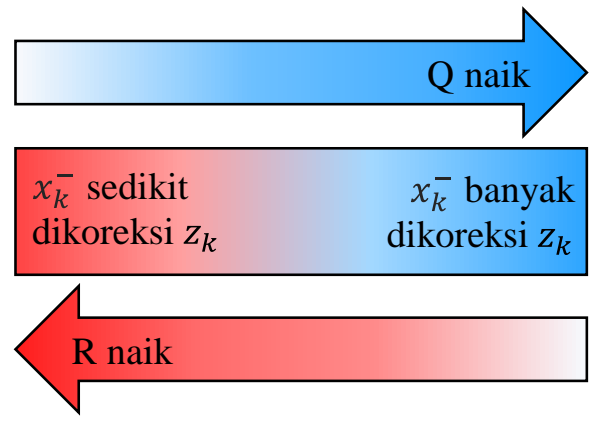

Gambar 2. Pengaruh nilai matriks Q dan R terhadap bobot koreksi Kalman filter.

Penelitian ini menggunakan dua Kalman filter. Kalman filter pertama digunakan untuk melakukan estimasi nilai orientasi UAV. Proses ini dilakukan dengan data fusion (penggabungan data) dari sensor akselerometer, magnetometer dan giroskop. Metode ini terbukti telah mampu digunakan untuk menentukan orientasi pada benda kaku [14]. Sementara itu, Kalman filter kedua digunakan untuk menentukan translasi (perpindahan) UAV. Proses ini dilakukan dengan data fusion dari data akselerometer dan GPS.

\subsection{Penentuan Sudut Orientasi}

Sudut orientasi merupakan besarnya sudut kemiringan suatu benda terhadap sudut referensi. Pada sebuah pesawat terbang, sudut orientasi terdiri dari attitude dan heading. Attitude terdiri dari sudut roll dan pitch, sedangkan heading merupakan sudut yaw. Pada penelitian ini, arah putaran ketiganya ditetapkan sebagaimana pada Gambar 3.

Sudut orientasi dapat diukur menggunakan sensor akselerometer, giroskop, dan magnetometer [15]. Ketiga sensor tersebut mempunyai karakteristik yang berbeda-beda. Sensor akselerometer dapat digunakan untuk mengukur kemiringan yang diakibatkan oleh percepatan yang ditimbulkan karena adanya gaya gravitasi (inklinasi). Sudut roll $(\phi)$ didefinisikan sebagai sudut dari sumbu y relatif ke bidang horizontal atau sudut putaran pada sumbu x, $R_{X}$. Sudut pitch $(\theta)$ didefinisikan sebagai sudut dari sumbu x relatif ke bidang horizontal atau sudut putaran pada sumbu y, $R_{y}$. 


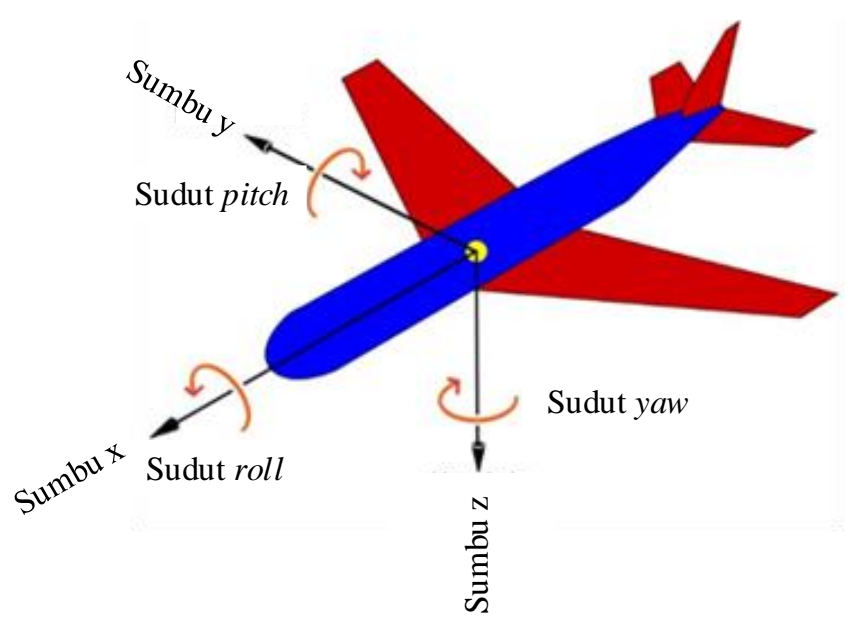

Gambar 3. Sudut gerakan roll, pitch, dan yaw

Sementara itu data dari sensor magnetometer dapat digunakan untuk mengukur sudut yaw. Sudut yaw $(\psi)$ didefinisikan sebagai sudut penyimpangan arah hadap terhadap arah utara kutub bumi atau sudut putaran pada sumbu z, $R_{z}$. Penentuan sudut roll $(\phi)$, pitch $(\theta)$, dan yaw $(\psi)$ dapat menggunakan data dari sensor akselerometer dan magnetometer berdasar Persamaan (1), (2) dan (3) [16].

$$
\begin{aligned}
& \phi=\arctan \left(\frac{a_{y}}{\sqrt{a_{x}^{2}+a_{z}^{2}}}\right) \\
& \theta=\arctan \left(\frac{a_{x}}{\sqrt{a_{y}^{2}+a_{z}^{2}}}\right) \\
& \psi=\arctan \left(\frac{x y m_{y}}{x y} m_{x}\right)-D
\end{aligned}
$$

dengan $a_{x}$ merupakan data percepatan dalam sumbu x, $a_{y}$ adalah data percepatan dalam sumbu $\mathrm{y}$, dan $a_{z}$ adalah data percepatan dalam sumbu z. Sementara itu, $D$ adalah sudut deklinasi arah medan magnet bumi. Nilai ini mendekati nol untuk wilayah Indonesia, sehingga dapat diabaikan.

${ }^{x y} m_{i}$ merupakan komponen medan magnet bumi dalam koordinat navigasi xy. Nilai ini didapat dari merotasikan data medan magnet bumi pada sumbu $\mathrm{x}$ dan $\mathrm{y}$. Nilai ini dapat dihitung dengan mengalikan matriks rotasi pada sumbu $\mathrm{y}, R_{Y}(\theta)$ dan matriks rotasi pada sumbu $\mathrm{x}$, $R_{X}(\phi)$ terhadap komponen medan magnet yang didapat dari data sensor magnetometer $m_{i}$ sebagaimana Persamaan (4).

$$
\begin{aligned}
{ }^{x y} m_{i} & =R_{Y}(\theta) \cdot R_{X}(\phi) \cdot m_{i} \\
& =\left[\begin{array}{ccc}
\cos \theta & 0 & \sin \theta \\
0 & 1 & 0 \\
-\sin \theta & 0 & \cos \theta
\end{array}\right]\left[\begin{array}{ccc}
1 & 0 & 0 \\
0 & \cos \phi & -\sin \phi \\
0 & \sin \phi & \cos \phi
\end{array}\right] m_{i} \\
& =\left[\begin{array}{ccc}
\cos \theta & \sin \phi \sin \theta & \cos \phi \sin \theta \\
0 & \cos \phi & -\sin \phi \\
-\sin \theta & \sin \phi \cos \theta & \cos \phi \cos \theta
\end{array}\right] m_{i}
\end{aligned}
$$


Sudut orientasi juga dapat dihitung menggunakan data kecepatan sudut dari sensor giroskop. Dengan menentukan nilai sudut awal, data sudut berjalan dapat ditentukan dengan mengintegralkan/mempropagasikan data kecepatan sudut. Namun metode ini mempunyai kelemahan. Adanya galat dari data kecepatan sudut akan terakumulasi, sehingga nilai galat sudut berjalan akan semakin besar.

Untuk mengurangi ketidaktepatan data orientasi dari sensor akselerometer dan magnetometer dan galat sudut dari data giroskop, maka dilakukanlah data fusion berbasis Kalman filter. Filter pertama ini digunakan untuk melakukan prediksi nilai sudut orientasi berdasar data kecepatan sudut dari sensor giroskop dan melakukan koreksi menggunakan data nilai sudut orientasi dari hasil hitungan dari sensor akselerometer dan magnetometer. Untuk mewujudkan hal tersebut ditetapkanlah sebuah prediksi state $x_{k}^{-}$sebagaimana Persamaan (5).

$$
x_{k}^{-}=\left[\begin{array}{llllll}
\phi & \dot{\phi} & \theta & \dot{\theta} & \psi & \dot{\psi}
\end{array}\right]^{\mathrm{T}}
$$

dengan $\phi, \theta$, dan $\psi$ merupakan sudut roll, pitch dan yaw saat ini, sedangkan $\dot{\phi}, \dot{\theta}$, dan $\dot{\psi}$ merupakan kecepatan sudut roll, pitch dan yaw dari keluaran giroskop. Dikarenakan giroskop tidak dapat digunakan untuk menentukan sudut orientasi secara langsung, maka nilai inisial sudut orientasi ditentukan dari sensor akselerometer dan magnetometer berdasarkan Persamaan (1) - (3).

Untuk dapat mempropagasikan nilai kecepatan sudut ke nilai sudut, matriks transisi $F$ dan matriks kontrol masukan $G$ Kalman filter ditentukan mengikuti Persamaan (6) dan (7).

$$
\begin{aligned}
F_{\text {ori }} & =\left[\begin{array}{cccccc}
1 & \Delta t & 0 & 0 & 0 & 0 \\
0 & 0 & 0 & 0 & 0 & 0 \\
0 & 0 & 1 & \Delta t & 0 & 0 \\
0 & 0 & 0 & 0 & 0 & 0 \\
0 & 0 & 0 & 0 & 1 & \Delta t \\
0 & 0 & 0 & 0 & 0 & 0
\end{array}\right] \\
G_{\text {ori }} & =\left[\begin{array}{lll}
0 & 0 & 0 \\
1 & 0 & 0 \\
0 & 0 & 0 \\
0 & 1 & 0 \\
0 & 0 & 0 \\
0 & 0 & 1
\end{array}\right]
\end{aligned}
$$

$\Delta t$ merupakan periode cuplikan data dalam detik.

Matriks kovarian derau proses mengikuti Persamaan (8).

$$
Q_{\text {ori }}=\left[\begin{array}{ccc}
Q_{i} & 0_{22} & 0_{22} \\
0_{22} & Q_{i} & 0_{22} \\
0_{22} & 0_{22} & Q_{i}
\end{array}\right]
$$

dengan $0_{22}$ adalah matriks nol $2 \times 2$ dan $Q_{i}$ merupakan matriks observasi roll, pitch dan yaw.

$$
Q_{i}=\left[\begin{array}{cc}
\frac{\Delta t^{3}}{3} & \frac{\Delta t^{2}}{2} \\
\frac{\Delta t^{2}}{2} & \Delta t
\end{array}\right]
$$

Matriks transisi $H_{\text {ori }}$ mengikuti Persamaan (10). 


$$
H_{\text {ori }}=\left[\begin{array}{llllll}
1 & 0 & 0 & 0 & 0 & 0 \\
0 & 0 & 1 & 0 & 0 & 0 \\
0 & 0 & 0 & 0 & 1 & 0
\end{array}\right]
$$

Matriks kovarian derau pengukuran ditetapkan berisi diagonal dari kovarian derau data orientasi saat sensor dalam kondisi statis. Nilai ini menjadi nilai $R_{\text {ori (default) }}$ sebagaimana Persamaan (11).

$$
R_{\text {ori (default })}=\operatorname{diag}\left[\operatorname{cov}\left(\phi_{\text {idle }}\right) \operatorname{cov}\left(\theta_{\text {idle }}\right) \operatorname{cov}\left(\psi_{\text {idle }}\right)\right]
$$

Data pengukuran sudut roll, pitch dan yaw $z_{k}$ didapat dari sensor akselerometer dan magnetometer sebagaimana Persamaan (1), (2) dan (3). Pada data fusion, data tersebut digunakan untuk melakukan koreksi atau update vektor prediksi state sebagaimana Gambar 2.

Penentuan sudut roll dan pitch menggunakan Persamaan (1) dan (2) pada hakikatnya adalah penentuan kemiringan sensor terhadap arah gaya gravitasi bumi. Persamaan tersebut hanya akurat pada saat sensor akselerometer dalam keadaan statis sehingga hanya percepatan gravitasi saja yang bekerja di sensor. Adanya percepatan linear yang bekerja pada sensor akselerometer dapat menjadikan adanya kesalahan pada perhitungan di kedua Persamaan tersebut. Dengan demikian, data pengukuran sudut roll dan pitch mestinya hanya digunakan saat sensor statis. Kalman filter harus memberikan bobot besar kepada data hasil pengukuran $z_{k}$ pada saat sensor statis. Dengan kata lain, dalam kondisi statis, Kalman filter harus memberikan bobot yang besar kepada Persamaan (1), (2) dan (3). Sedangkan dalam kondisi dinamis, Kalman filter harus memberikan bobot yang besar pada proses prediksi state sebagai hasil propagasi nilai kecepatan sudut dari data giroskop.

Untuk mewujudkan hal tersebut, dilakukan pengubahan nilai kovarian derau pengukuran $R_{\text {ori }}$. Hal ini merupakan pengembangan dari penelitian sebelumnya [17]. Pada saat sensor dinyatakan dalam kondisi dinamis, $R_{\text {ori }}$ sama dengan $R_{\text {ori (default) }}$. Nilai prediksi $x_{k}^{-}$tidak akan banyak dikoreksi oleh $z_{k}$ atau dengan kata lain Kalman filter memberikan bobot cukup besar pada nilai prediksi $x_{k}^{-}$. Sementara itu, dalam kondisi statis nilai $R_{\text {ori }}$ dijadikan 0,1

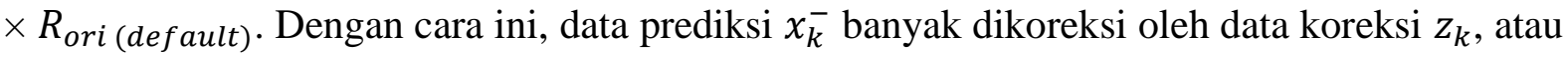
Kalman filter memberikan bobot yang besar bagi nilai orientasi yang didapat dari sensor akselerometer dan magnetometer.

\subsection{Penentuan Kondisi Sensor}

Kondisi statis atau dinamis sensor dapat dideteksi dengan mengukur kovarian nilai percepatan. Kondisi dinamis ditandai adanya percepatan linear yang bekerja pada sensor. Adanya percepatan linear yang bekerja pada sensor menjadikan nilai percepatan berubah-ubah. Pendeteksian besarnya perubahan nilai percepatan dapat dilakukan dengan menghitung kovarian data percepatan. Untuk itu, telah dikembangkan algoritma untuk menentukan nilai kovarian berjalan (moving covarian) atas data percepatan. Moving covariance menghitung nilai kovarian atas nilai data percepatan untuk beberapa data terakhir. Banyaknya data terakhir yang digunakan untuk menentukan nilai kovarian didefinisikan sebagai $w$. Nilai total moving covariance ketiga sumbu dapat dihitung menggunakan Persamaan (12).

$$
\sigma_{a}=\sum \operatorname{cov}\left(a_{i:(k-w) \sim k}\right)
$$

dengan: $\sigma_{a}=$ total kovarian nilai percepatan untuk ketiga sumbu

$a_{i}=$ data percepatan setiap sumbu

$k=$ indeks saat ini

$w=$ lebar jendela kovarian atau banyak data yang dihitung 
Nilai kovarian tersebut dibandingkan dengan nilai batas (threshold). Jika nilai kovarian kurang dari nilai batas $\sigma_{t h}$, maka sensor dinyatakan dalam keadaan statis. Hal ini berarti sensor tidak mengalami percepatan linear, meskipun sensor ini dapat mengalami translasi dengan kecepatan konstan.

\subsection{Penentuan Translasi UAV}

Penentuan translasi UAV dapat dilakukan menggunakan metode dead reckoning. Metode ini dilakukan dengan mengintegrasikan/mempropagasikan data percepatan dari sensor akselerometer untuk mengestimasi posisi baru berdasarkan posisi awal yang telah diketahui. Translasi juga dapat ditentukan berdasar data lokasi dari sensor GPS. Agar didapat nilai lebih tepat, maka proses penentuan translasi dilakukan menggunakan data fusion berbasis Kalman filter kedua. Selain dapat mengurangi derau dari sensor IMU [18], filter ini digunakan untuk menggabungkan data dari akselerometer dan GPS. Pada Kalman filter kedua ini, nilai percepatan yang sudah dikonversi ke dalam koordinat navigasi dijadikan sebagai data prediksi dan nilai translasi yang dihitung dari data lokasi yang didapat dari sensor GPS dijadikan sebagai data pengoreksi.

Sensor akselerometer mengukur percepatan pada sumbu x, y, dan z. Dari nilai percepatan tersebut dapat ditentukan percepatan yang bekerja dalam koordinat navigasi menggunakan Persamaan (13).

$$
\begin{aligned}
{\left[\begin{array}{l}
{ }^{N} a_{x} \\
{ }^{N} a_{y} \\
{ }^{N} a_{z}
\end{array}\right] } & =R_{B}^{N}\left[\begin{array}{l}
a_{x} \\
a_{y} \\
a_{z}
\end{array}\right]-g \\
& =R_{B}^{N}\left[\begin{array}{l}
a_{x} \\
a_{y} \\
a_{z}
\end{array}\right]-\left[\begin{array}{c}
0 \\
0 \\
-|g|
\end{array}\right]
\end{aligned}
$$

dengan $g$ merupakan percepatan gravitasi bumi.

$R_{B}^{N}$ merupakan matriks rotasi yang dapat ditentukan menggunakan Persamaan (14).

$$
\begin{aligned}
& R_{B}^{N}=R_{Z}(\psi), R_{Y}(\theta), R_{X}(\phi) \\
& =\left[\begin{array}{ccc}
\cos \theta \cos \psi & \sin \phi \sin \theta \cos \psi-\cos \phi \sin \psi & \cos \phi \sin \theta \cos \psi+\sin \phi \sin \psi \\
\cos \theta \sin \psi & \sin \phi \sin \theta \sin \psi+\cos \phi \cos \psi & \cos \phi \sin \theta \sin \psi-\sin \phi \cos \psi \\
-\sin \theta & \sin \phi \cos \theta & \cos \phi \cos \theta
\end{array}\right]
\end{aligned}
$$

State prediksi pada Kalman filter ini mengikuti Persamaan (15)

$$
x_{k}^{-}=\left[\begin{array}{lllllllll}
{ }^{N} S_{x} & { }^{N} S_{y} & { }^{N} S_{z} & { }^{N} v_{x} & { }^{N} v_{y} & { }^{N} v_{z} & { }^{N} a_{x} & { }^{N} a_{y} & { }^{N} a_{z}
\end{array}\right]^{T}
$$

dengan: ${ }^{N} S_{x},{ }^{N} S_{y}$, dan ${ }^{N} S_{z}$ merupakan translasi pada sumbu x, sumbu y, dan sumbu z

${ }^{N} v_{x},{ }^{N} v_{y}$, dan ${ }^{N} v_{z}$ adalah kecepatan pada sumbu x, sumbu y, dan sumbu z

${ }^{N} a_{x},{ }^{N} a_{y}$, dan ${ }^{N} a_{z}$ adalah percepatan pada sumbu x, sumbu y, dan sumbu z.

Semua nilai dalam state tersebut merupakan nilai dalam koordinat navigasi NED (North East Down). Agar nilai percepatan ${ }^{N} a_{i}$ dapat dipropagasikan menjadi nilai kecepatan ${ }^{N} v_{i}$ dan translasi ${ }^{N} S_{i}$, maka ditetapkanlah matriks transisi $F_{\text {trans }}$ dan matriks kontrol masukan $G_{\text {trans }}$ sebagaimana Persamaan (16) dan (17) berikut. 


$$
\begin{aligned}
F_{\text {trans }} & =\left[\begin{array}{ccccccccc}
1 & \Delta t & \Delta t^{2} / 2 & 0 & 0 & 0 & 0 & 0 & 0 \\
0 & 1 & \Delta t & 0 & 0 & 0 & 0 & 0 & 0 \\
0 & 0 & 0 & 0 & 0 & 0 & 0 & 0 & 0 \\
0 & 0 & 0 & 1 & \Delta t & \Delta t^{2} / 2 & 0 & 0 & 0 \\
0 & 0 & 0 & 0 & 1 & \Delta t & 0 & 0 & 0 \\
0 & 0 & 0 & 0 & 0 & 0 & 0 & 0 & 0 \\
0 & 0 & 0 & 0 & 0 & 0 & 1 & \Delta t & \Delta t^{2} / 2 \\
0 & 0 & 0 & 0 & 0 & 0 & 0 & 1 & \Delta t \\
0 & 0 & 0 & 0 & 0 & 0 & 0 & 0 & 0
\end{array}\right] \\
G_{\text {trans }} & =\left[\begin{array}{lll}
0 & 0 & 0 \\
0 & 0 & 0 \\
1 & 0 & 0 \\
0 & 0 & 0 \\
0 & 0 & 0 \\
0 & 1 & 0 \\
0 & 0 & 0 \\
0 & 0 & 0 \\
0 & 0 & 1
\end{array}\right]
\end{aligned}
$$

Matriks pengukuran dan kovarian derau proses mengikuti Persamaan (18) dan (19).

$$
\begin{aligned}
H_{\text {trans }} & =\left[\begin{array}{ccccccccc}
1 & 0 & 0 & 0 & 0 & 0 & 0 & 0 & 0 \\
0 & 0 & 0 & 1 & 0 & 0 & 0 & 0 & 0 \\
0 & 0 & 0 & 0 & 0 & 0 & 1 & 0 & 0
\end{array}\right] \\
Q_{\text {trans }} & =\left[\begin{array}{cccc}
Q_{i} & 0_{3 \times 3} & 0_{3 \times 3} \\
0_{3 \times 3} & Q_{i} & 0_{3 \times 3} \\
0_{3 \times 3} & 0_{3 \times 3} & Q_{i}
\end{array}\right]
\end{aligned}
$$

dengan

$$
Q_{i}=\left[\begin{array}{ccc}
\Delta t^{5} / 20 & \Delta t^{4} / 8 & \Delta t^{3} / 3 \\
\Delta t^{4} / 8 & \Delta t^{3} / 3 & \Delta t^{2} / 2 \\
\Delta t^{3} / 6 & \Delta t^{2} / 2 & \Delta t
\end{array}\right]
$$

Data pengukuran translasi dalam arah ketiga sumbu $z_{k}$ didapat dari sensor GPS. Pada saat sistem diaktifkan, GPS memberikan data awal sebagai data inisial. Data dari GPS berikutnya mengacu kepada data inisial ini sehingga dapat dihitung jarak translasi. Data dari GPS merupakan lokasi UAV yang terdiri dari data derajat lintang, derajat bujur dan ketinggian. Jika terdapat dua titik di permukaan bumi, maka menurut koordinat navigasi, jarak dalam arah $\mathrm{x}$ (utara - selatan) dapat dihitung dengan menghitung selisih garis lintang. Sedangkan jarak dalam arah y (timur - barat) dapat dihitung dari selisih garis bujur. Jarak per derajat lintang hampir sama di semua permukaan bumi, sementara itu jarak per derajat bujur akan menjadi lebih kecil dengan semakin dekat tempat tersebut ke kutub bumi. Untuk daerah di sekitar khatulistiwa, jarak per derajat lintang dan bujur mendekati sama.

Untuk dua titik di permukaan bumi dengan jarak lintang atau bujur A, jarak kedua titik tersebut dapat ditentukan menggunakan Persamaan (21). 


$$
\Delta L=\frac{2 \pi r A}{360}
$$

dengan: $\Delta L=$ jarak dalam meter

$r=$ jari-jari bumi yaitu 6.371 kilometer

$A=$ jarak dalam derajat lintang atau bujur

Dari Persamaan (21) didapat bahwa setiap perubahan derajat lintang dan bujur di khatulistiwa akan terdapat perubahan jarak sekitar $\Delta L=111.195$ meter.

Sementara itu, sensor akselerometer dapat memberikan data hingga 202 data/detik; sedangkan sensor GPS hanya dapat memberikan 1 data/detik. Pada saat tidak tersedia data GPS, Kalman filter harus memberikan bobot yang sangat besar pada data prediksi sebagai hasil propagasi dari data percepatan.

Dalam percobaan, posisi UAV diterbangkan dengan ketinggian sekitar 30 meter di atas permukaan tanah. Dalam kondisi ini, UAV sudah berada di atas gedung yang ada. Diasumsikan jumlah satelit GPS yang dapat mengirim data ke sensor GPS secara line-on-sight (LOS) sudah cukup banyak sehingga GPS dapat memberikan data lokasi dengan tepat. Oleh karena itu, data lokasi dari sensor GPS diasumsikan dapat dipercaya. Untuk itu, Kalman filter harus memberikan bobot besar kepada data tersebut.

Sebagaimana telah dipaparkan di muka, nilai matriks kovarian derau pengukuran $R$ dapat menentukan seberapa besar Kalman filter memberikan bobot pada nilai prediksi atau nilai koreksi dari data pengukuran. Untuk dapat memberikan bobot dengan nilai cukup besar, maka nilai $R$ dapat ditentukan secara manual. Dalam hal ini telah ditetapkan $R_{\text {trans(default) }}$ dengan nilai cukup besar. Nilai ini berlaku saat tidak ada data dari sensor GPS sehingga Kalman filter memberikan bobot yang sangat besar pada data prediksi sebagai hasil propagasi dari data percepatan. Sementara itu, nilai tersebut dikalikan dengan konstanta yang cukup kecil pada saat terdapat data baru dari sensor GPS sehingga Kalman filter memberikan bobot yang sangat besar pada data koreksi yang berasal dari data lokasi dari sensor GPS.

\section{Hasil dan Pembahasan}

\subsection{Orientasi UAV}

Penelitian ini difokuskan pada penentuan sudut orientasi dan translasi UAV berjenis quadrotor. Sudut orientasi yang dimaksud meliputi sudut roll, pitch dan yaw. Sedangkan translasi UAV merupakan perpindahan UAV dalam koordinat navigasi. Dari data translasi nantinya dapat ditentukan lintasan UAV.

Percobaan dilakukan dengan lokasi di halaman tengah Kampus Institut Teknologi Dirgantara Adisutjipto. Koordinat titik awal jalur penerbangan berdasar data yang didapat dari data sensor GPS adalah $7^{\circ} 47^{\prime} 49.4448^{\prime \prime}$ LS dan $110^{\circ} 22^{\prime} 13.9044^{\prime \prime}$ BT dengan ketinggian 122,6 meter di atas permukaan laut. Data lokasi ini menjadi lokasi inisial sehingga menjadi state inisial $x_{0}$ pada Kalman filter kedua.

Percobaan ini menggunakan sensor pada smartphone untuk merekam data percepatan, kecepatan sudut, medan magnet bumi, dan data lokasi dari GPS. Untuk dapat merekam secara detail manuver UAV, semua sensor dioperasikan dengan frekuensi cuplikan tertinggi yang mampu dieksekusi oleh sensor sebagaimana Tabel 1. Data dari semua sensor diproses dengan frekuensi cuplikan (sampling) 202,1 Hz atau mempunyai jeda waktu $\Delta t=4,9$ milidetik agar grafik dapat mempunyai resolusi tinggi. Dikarenakan sensor giroskop, magnetometer dan GPS mempunyai frekuensi cuplikan yang lebih rendah, maka digunakanlah sebuah algoritma khusus untuk membentuk data tiruan (dummy) yang berfungsi menyisipkan beberapa data pada data giroskop, magnetometer dan juga data lokasi dari sensor GPS agar mempunyai jeda waktu yang sama dengan data akselerometer. 
Tabel 1. Tabel parameter percobaan penentuan attitude UAV

\begin{tabular}{l|c|r}
\hline \multicolumn{1}{c|}{ Parameter } & Notasi & \multicolumn{1}{c}{ Nilai } \\
\hline Frekuensi cuplikan akselerometer & $f_{\text {S:acc }}$ & $202,1 \mathrm{~Hz}$ \\
\hline Frekuensi cuplikan giroskop & $f_{S: \text { gyro }}$ & $50,8 \mathrm{~Hz}$ \\
\hline Frekuensi cuplikan magnetometer & $f_{S: m a g}$ & $50,8 \mathrm{~Hz}$ \\
\hline Frekuensi cuplikan sensor GPS & $f_{S: G P S}$ & $1 \mathrm{~Hz}$ \\
\hline Nilai batas kovarian percepatan & $\sigma_{t h}$ & 0,11 \\
\hline Delta waktu & $\Delta t$ & 4,9 milidetik \\
\hline Lebar jendela kovarian & $w$ & 0,118 detik \\
\hline
\end{tabular}

Penentuan kondisi statis (dalam arti tidak terdapat percepatan) pada sensor dilakukan dengan mengukur nilai total kovarian percepatan pada ketiga sumbu untuk rentang waktu $w=$ 0,118 detik terakhir. Pada percobaan ini digunakan batas kovarian percepatan sebesar $\sigma_{t h}=$ 0,11 . Dengan demikian, jika $\sigma_{a}$ dari Persamaan (12) kurang dari 0,11, maka sensor dinyatakan dalam kondisi statis.

Pada percobaan ini, UAV diterbangkan membentuk lintasan mendekati bentuk bujur sangkar dengan sisi 30 meter dan kemiringan $6^{\circ}$ terhadap arah utara, dan dengan ketinggian 30 meter seperti Gambar 4. UAV diterbangkan dengan kecepatan rata-rata sekitar $6 \mathrm{~km} / \mathrm{jam}$ dan berhenti sekitar 1 detik di setiap sudut bujur-sangkar. Untuk menempuh lintasan tersebut, dibutuhkan waktu sekitar 80 detik.

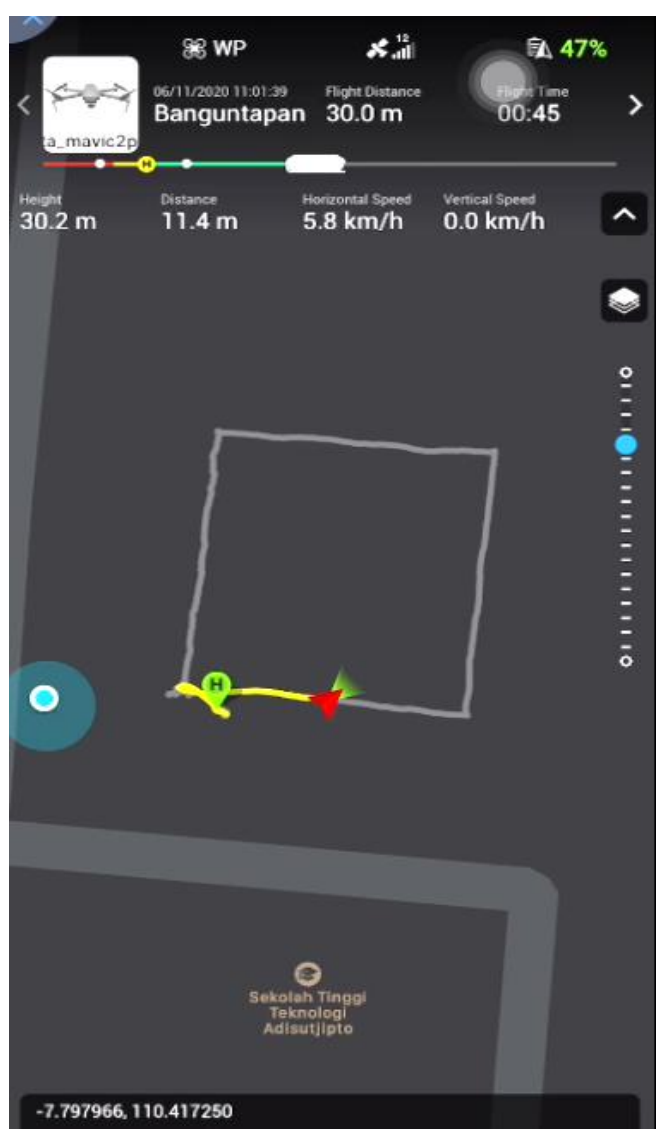

Gambar 4. Tampilan lintasan UAV sebagaimana terlihat di kontroler UAV

UAV digerakkan ke arah timur hingga sejauh 30 meter pada saat $t=0 \sim 20$ detik. Dikarenakan lintasan bujur sangkar UAV membentuk sudut $6^{\circ}$, maka gerakan ke timur ini 
diikuti dengan gerakan ke arah selatan sejauh 2 meter. Pada saat gerakan ke timur ini juga sekaligus dilakukan perputaran arah hadap (yaw) sehingga Sudut hadap UAV yang tadinya ke timur $\left(90^{\circ}\right)$ menjadi ke arah utara $\left(0^{\circ}\right)$.

Setelah mencapai titik paling timur, UAV dihentikan selama 1 detik. Kemudian UAV digerakkan ke arah utara sejauh 30 meter. Pada saat gerakan ke utara ini juga sekaligus dilakukan perputaran arah hadap sehingga sudut hadap yang tadinya ke utara $\left(0^{\circ}\right)$ menjadi ke arah barat $\left(-90^{\circ}\right)$. Di titik paling utara, UAV dihentikan selama 1 detik untuk kemudian digerakkan ke arah barat sejauh 30 meter. Gerakan ke barat ini juga sekaligus dilakukan perputaran arah hadap sehingga sudut hadap yang tadinya ke barat $\left(-90^{\circ}\right)$ menjadi ke arah selatan $\left(180^{\circ}\right)$. Sesampainya di titik paling barat, UAV dihentikan selama 1 detik untuk kemudian digerakkan ke selatan sejauh 30 meter. Tidak seperti gerakan sebelumnya, gerakan ke arah selatan ini tidak mengubah arah hadap UAV.

Data sensor selama penerbangan disajikan pada Gambar 5. Grafik percepatan, kecepatan sudut dan medan magnet merupakan nilai dalam koordinat sensor. Sesuai dengan kaidah arah dalam koordinat sensor sebagaimana Gambar 3, grafik percepatan terdiri dari data percepatan dan medan magnet untuk arah sumbu x (arah maju), y (ke kanan) dan z (bawah). Sementara itu, grafik kecepatan sudut terdiri dari data kecepatan putar pada sumbu x (roll), sumbu y (pitch) dan z (yaw). Sedangkan grafik medan magnet merupakan data medan magnet yang terdeteksi sensor untuk komponen ke arah sumbu x (arah maju), y (ke kanan) dan $\mathrm{z}$ (bawah).
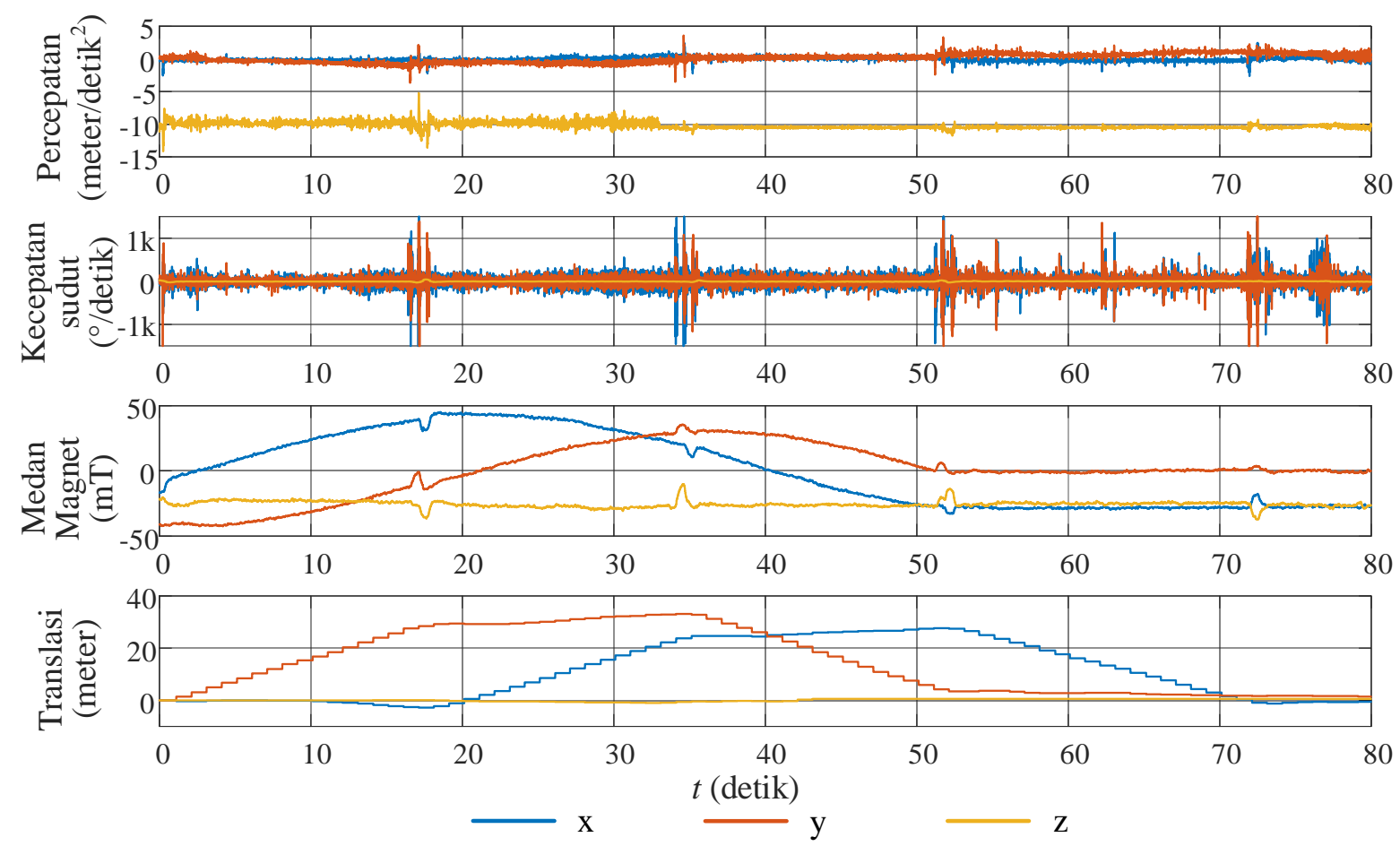

Gambar 5 Grafik data dari sensor akselerometer, giroskop, magnetometer dan GPS

Sementara itu, grafik translasi merupakan nilai relatif terhadap titik inisial dan didapat dari data lokasi dari sensor GPS. Data ini merupakan hasil perhitungan selisih derajat lintang, garis bujur dan ketinggian saat ini dengan derajat lintang bujur, dan ketinggian inisial mengikuti Persamaan (21).

Nilai orientasi selama penerbangan dapat dilihat pada Gambar 6. Grafik paling atas menggambarkan nilai orientasi sebagai hasil propagasi dari data kecepatan sudut yang didapat 
dari sensor giroskop. Grafik kedua menggambarkan nilai orientasi hasil perhitungan dari data percepatan dan medan magnet mengikuti Persamaan (1) - (3). Grafik ketiga menggambarkan nilai orientasi dari Kalman filter. Sementara grafik paling bawah menggambarkan nilai orientasi hasil perhitungan dari perangkat lunak IMU+GPS Stream di smartphone. Nilai orientasi ini dijadikan sebagai nilai validator atas ketepatan nilai orientasi.

Dari grafik orientasi dari sensor giroskop terlihat bahwa nilai orientasi mempunyai penyimpangan cukup besar. Penyimpangan ini akan semakin besar dengan bertambahnya waktu. Sementara itu, dari grafik orientasi dari sensor akselerometer dan magnetometer, terlihat bahwa bentuk grafik tersebut lebih mendekati bentuk grafik orientasi validator. Namun nilai orientasi ini dapat menjadi berfluktuasi saat arah hadap UAV ke selatan, yaitu pada saat sudut yaw berubah-ubah dari $180^{\circ} \mathrm{ke}-180^{\circ}$ dan sebaliknya.
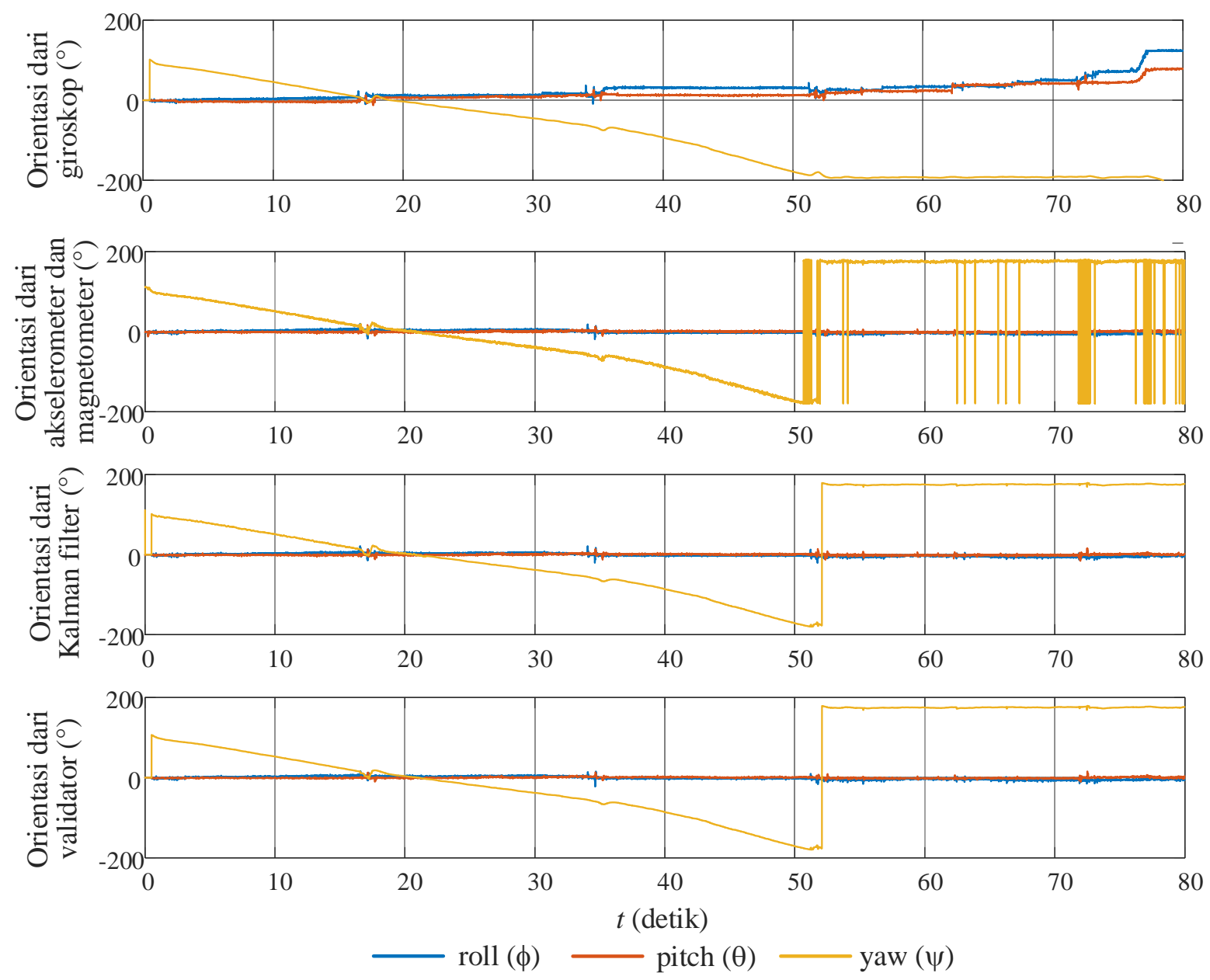

Gambar 6. Grafik sudut orientasi gerakan UAV

Kalman filter pertama digunakan untuk mengestimasi nilai orientasi. Di sini, nilai orientasi yang didapat dari sensor giroskop menjadi data prediksi orientasi, sementara itu nilai orientasi dari sensor akselerometer dan magnetometer dijadikan data untuk mengoreksi data prediksi orientasi. Data fusion menggunakan Kalman filter ini menghasilkan grafik estimasi nilai orientasi seperti terlihat pada grafik ketiga pada Gambar 6.

Dari hasil percobaan, didapat bahwa penghitungan nilai orientasi dengan menggunakan data dari sensor giroskop saja menghasilkan galat absolut untuk nilai roll, pitch dan yaw cukup tinggi dengan rerata $18,12^{\circ}$. Nilai galat untuk ketiga sudut ini dapat dilihat pada Tabel 2. Sementara itu, perhitungan nilai orientasi yang menggunakan data dari sensor akselerometer 
dan magnetometer akan menghasilkan galat yang lebih rendah dengan rerata $1,30^{\circ}$. Dan galat dapat diturunkan lagi jika penghitungan nilai orientasi dilakukan dengan data fusion dari sensor giroskop, akselerometer dan magnetometer menggunakan Kalman filter. Rerata galat dengan metode ini hanya $0,87^{\circ}$

Tabel 2. Galat absolut nilai sudut orientasi.

\begin{tabular}{|c|c|c|c|c|}
\hline \multirow{2}{*}{ Data sensor yang digunakan } & \multicolumn{3}{|c|}{ Galat sudut orientasi } & \multirow{2}{*}{$\begin{array}{c}\text { Rerata } \\
\text { galat }\end{array}$} \\
\hline & Roll & Pitch & Yaw & \\
\hline Giroskop & $28,58^{\circ}$ & $18,30^{\circ}$ & $7,48^{\circ}$ & $18,12^{\circ}$ \\
\hline Akselerometer dan magnetometer & $1,37^{\circ}$ & $0,93^{\circ}$ & $1,61^{\circ}$ & $1,30^{\circ}$ \\
\hline Giroskop, akselerometer dan magnetometer & $1,28^{\circ}$ & $0,88^{\circ}$ & $0,47^{\circ}$ & $0,87^{\circ}$ \\
\hline
\end{tabular}

\subsection{Translasi UAV}

Nilai orientasi dimasukkan ke dalam matriks rotasi di Persamaan (14). Matriks rotasi dikalikan dengan percepatan yang didapat dari sensor akselerometer sehingga menghasilkan percepatan dalam koordinat navigasi. Selanjutnya percepatan ini dikurangi dengan nilai gravitasi sebagaimana Persamaan (13) sehingga didapatkan nilai percepatan yang sesungguhnya dalam koordinat navigasi ${ }^{N} a_{i}$. Kalman filter menggunakan nilai percepatan ini untuk dipropagasikan menjadi nilai kecepatan dan translasi dalam bentuk vektor nilai prediksi $x_{k}^{-}$. Sementara itu, data translasi dari sensor GPS dijadikan nilai hasil pengukuran $z_{k}$ yang digunakan untuk melakukan koreksi. Dikarenakan data GPS hanya di-update datu kali per detik, maka Kalman filter hanya memberikan bobot yang besar pada $z_{k}$ pada saat ada data baru dari GPS. Sebuah algoritme khusus digunakan untuk mendeteksi adanya data GPS. Pada saat terdapat data GPS, maka nilai $R$ dijadikan $0,01 \times R_{\text {trans(default) }}$. Dengan cara ini, data fusion memberikan bobot yang besar pada data dari GPS.

Nilai prediksi percepatan, kecepatan, dan translasi UAV dapat dilihat pada Gambar 7. Dari grafik kecepatan tidak terlihat secara cukup signifikan adanya gerakan UAV. Gerakan UAV hanya berkisar di bawah 0,5 meter/detik. Sementara itu, dengan semakin bertambahnya waktu, maka nilai kecepatan dan translasi akan semakin tinggi. Namun hal tersebut sesungguhnya tidak menggambarkan adanya gerakan UAV. Nilai kecepatan dan translasi yang tinggi untuk waktu di atas 60 detik lebih didominasi adanya akumulasi galat akibat proses propagasi pada metode dead reckoning.

Adanya derau sensor akselerometer dan akumulasi derau dari proses propagasi menyebabkan nilai prediksi translasi jauh berbeda dengan nilai translasi yang sesungguhnya. Adanya galat nilai prediksi juga disebabkan oleh adanya galat nilai sudut orientasi. Sebagaimana Persamaan (14), nilai sudut orientasi menentukan nilai setiap elemen matriks rotasi. Adanya galat sudut orientasi akan menyebabkan ketidaktepatan nilai elemen matriks rotasi dan akhirnya menyebabkan ketidaktepatan nilai percepatan dalam koordinat navigasi. Ketidaktepatan ini menyebabkan adanya galat pada nilai kecepatan dan translasi. 

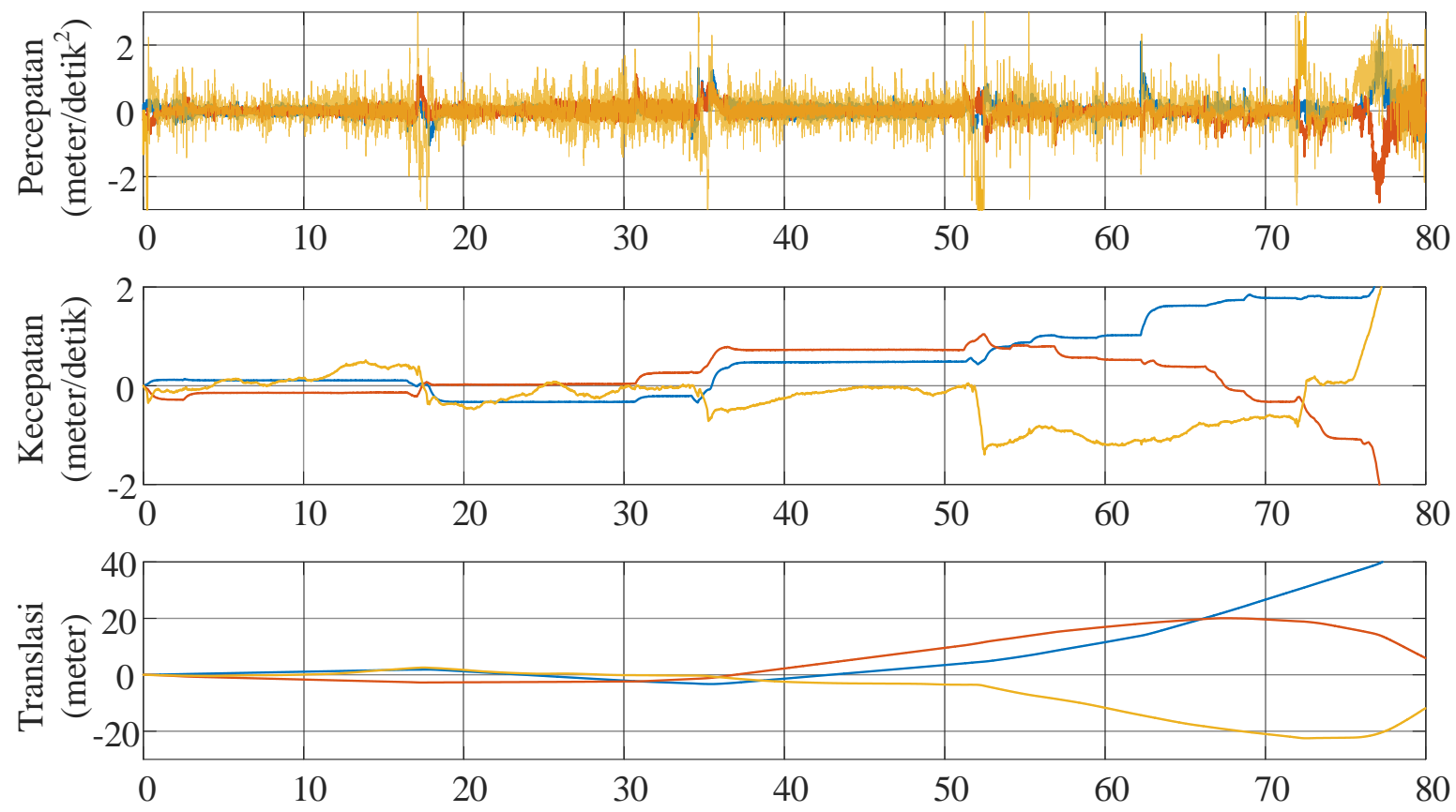

Gambar 7. Grafik prediksi percepatan, kecepatan dan translasi dalam koordinat navigasi

Untuk mengurangi galat, digunakanlah data fusion berbasis Kalman filter kedua. Adanya proses koreksi pada filter ini menjadikan nilai prediksi diperbarui secara periodik dengan cukup signifikan. Dalam hal ini, pemilihan nilai $R_{\text {trans(default) }}$ dan faktor pengali $R$ dapat mempengaruhi seberapa halus transisi grafik kecepatan dan translasi pada saat terjadi koreksi dari data GPS. Grafik estimasi percepatan, kecepatan dan translasi hasil koreksi Kalman filter dapat dilihat pada Gambar 8.
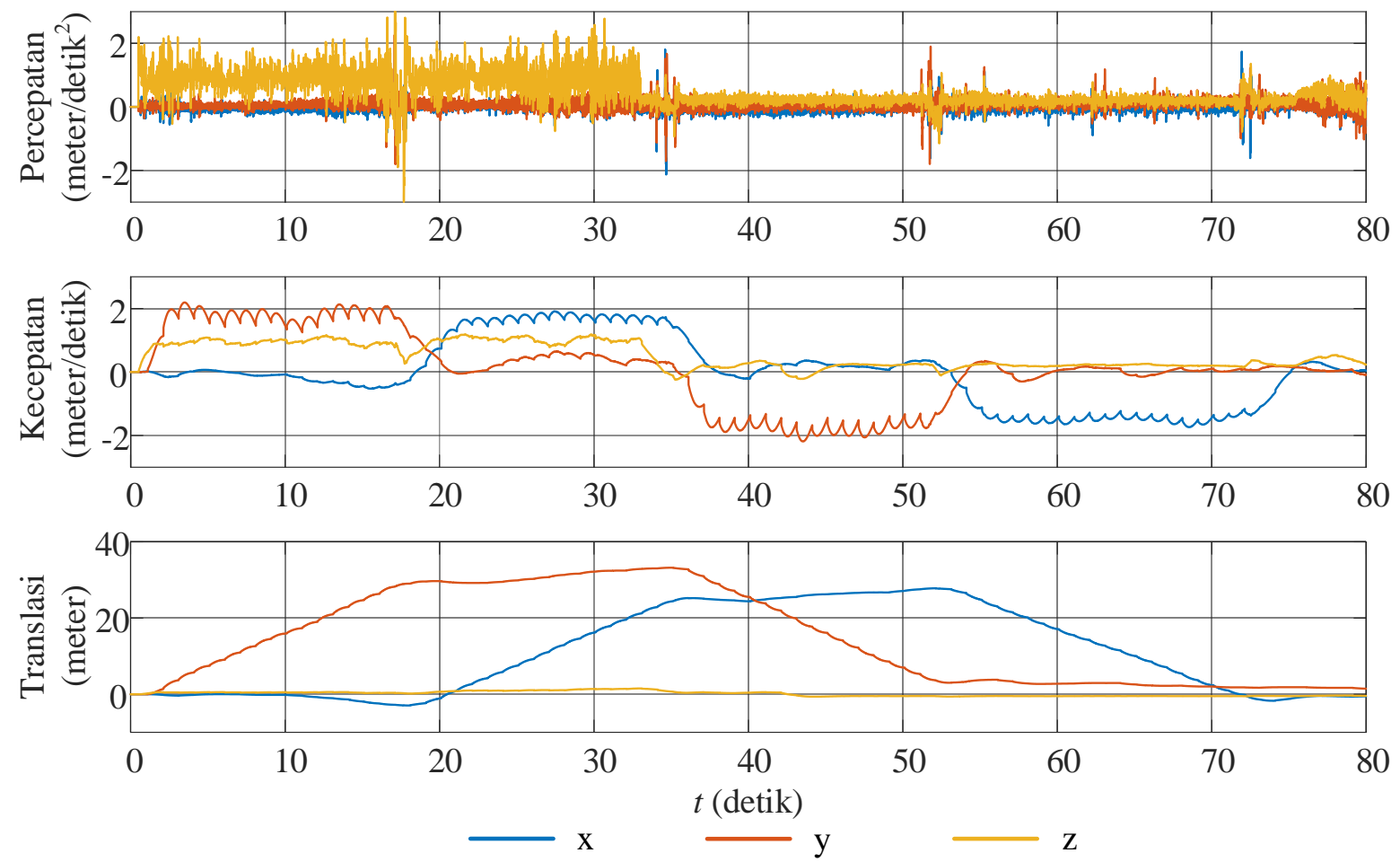

Gambar 8. Grafik estimasi percepatan, kecepatan dan translasi dalam koordinat navigasi dari Kalman filter 
Sebagaimana telah dipaparkan di muka, bahwa UAV ini bergerak dengan kecepatan 6 $\mathrm{km} / \mathrm{jam}$ atau 1,67 meter/detik. Dengan membandingkan grafik kecepatan pada Gambar 7 dan grafik kecepatan pada Gambar 8 terlihat bahwa proses data fusion berbasis Kalman filter telah dapat mengoreksi data kecepatan sehingga menghasilkan nilai dan arah kecepatan dengan lebih tepat. Sesuai dengan ketentuan arah setiap sumbu pada koordinat navigasi NED, terlihat adanya gerakan dengan kecepatan mendekati 2 meter/detik ke timur untuk $t=0 \sim 19$ detik. Gerakan ke timur ini ditandai dengan adanya nilai positif kecepatan pada sumbu y. Sementara itu, pada $t=19 \sim 37$ detik terlihat adanya gerakan dengan kecepatan hampir sama namun ke utara. Gerakan ke utara ini ditandai dengan adanya nilai positif kecepatan pada sumbu x. Selanjutnya berturut-turut juga terlihat adanya gerakan ke barat dan ke selatan yang ditandai dengan adanya nilai negatif kecepatan pada sumbu y dan $\mathrm{x}$.

Data translasi juga mengalami koreksi cukup signifikan. Dari grafik translasi pada Gambar 8 terlihat adanya gerakan ke arah positif pada sumbu x atau ke utara untuk $t=0 \sim 19$ detik, gerakan ke arah positif pada sumbu y atau ke timur untuk $t=19 \sim 37$ detik, dan selanjutnya berturut-turut gerakan ke barat dan selatan. Dengan data fusion berbasis Kalman filter, data percepatan dapat dipropagasikan dan digunakan untuk memprediksi data translasi pada saat data dari GPS tidak tersedia, sehingga grafik translasi pada Gambar 8 menjadi lebih presisi dibandingkan grafik translasi pada Gambar 7. Lintasan UAV dalam koordinat ruang dapat digambarkan dalam grafik tiga dimensi sebagaimana Gambar 9.

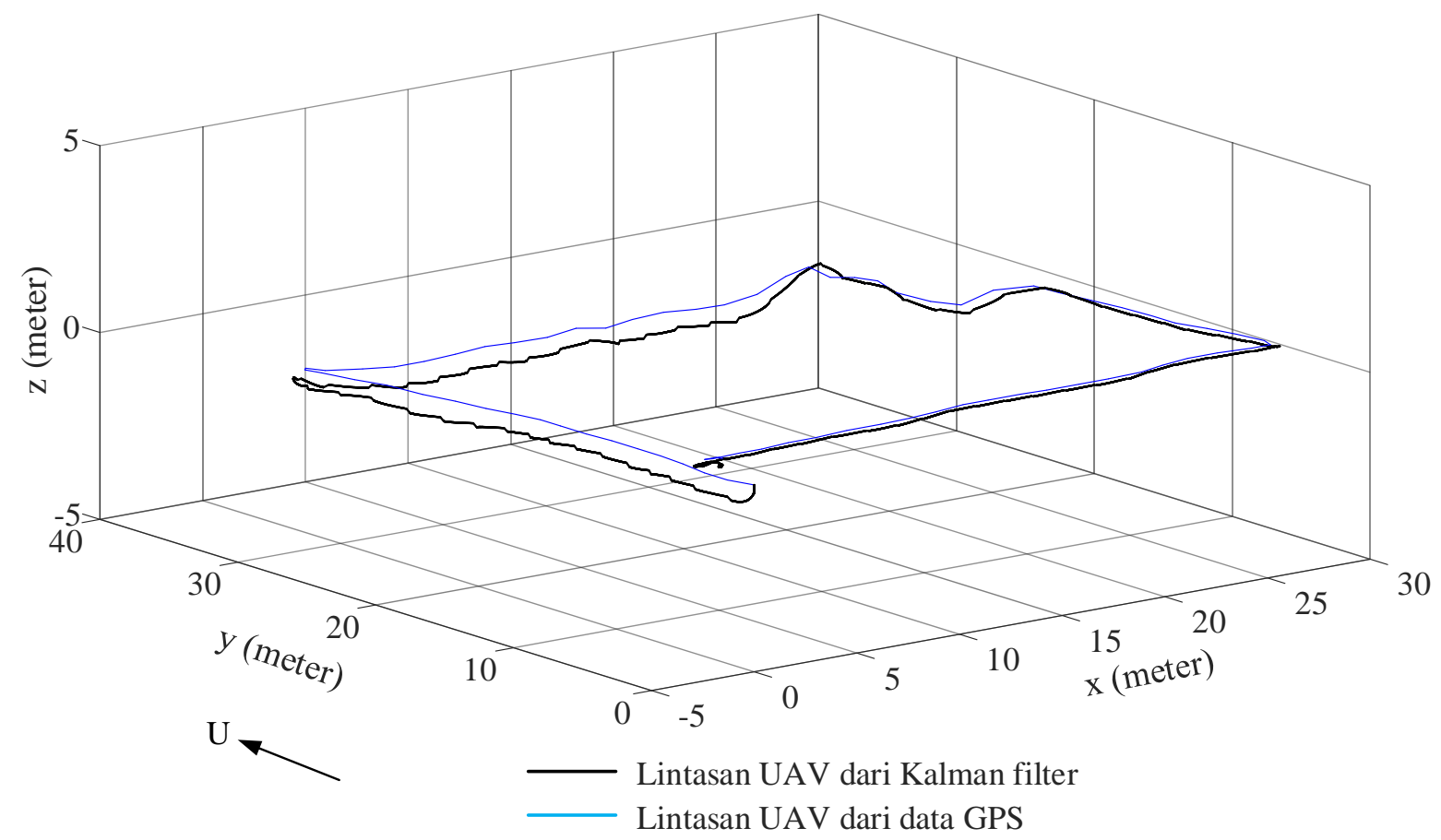

Gambar 9. Grafik lintasan UAV

\section{Kesimpulan}

Kalman filter dapat digunakan untuk mengestimasi nilai orientasi dan translasi UAV dengan melakukan data fusion atas data dari sensor akselerometer, giroskop, magnetometer, dan GPS. Pada proses estimasi sudut orientasi, data fusion dapat dilakukan dengan mempropagasikan data kecepatan sudut dari sensor giroskop menjadi data prediksi orientasi dan mengoreksinya dengan data sudut orientasi hasil perhitungan dari nilai percepatan dan medan magnet bumi. Keakurasian data orientasi ini dapat dijadikan lebih akurat dengan memberikan bobot yang lebih besar pada data koreksi pada saat sensor dalam keadaan statis 
dan memberikan bobot yang lebih besar pada proses propagasi pada saat sensor dalam keadaan dinamis. Nilai orientasi yang dihitung dari data sensor giroskop mempunyai rerata galat $18,12^{\circ}$, sedangkan nilai orientasi dari data sensor akselerometer dan magnetometer mempunyai retata galat $1,30^{\circ}$. Galat nilai orientasi dapat diturunkan menjadi $0,87^{\circ}$ dengan proses data fusion berbasis Kalman filter. Sementara itu, pada proses penentuan data translasi UAV, data fusion dapat dilakukan dengan mempropagasikan data percepatan dalam koordinat navigasi dan mengoreksinya dengan data lokasi dari sensor GPS. Dengan data fusion, nilai translasi hasil propagasi dari data percepatan dapat mengisi nilai translasi UAV pada saat data GPS tidak tersedia. Di lain waktu, data fusion harus memberikan bobot yang besar pada data GPS saat terdapat data baru dari sensor GPS agar didapat nilai estimasi translasi yang lebih tepat.

\section{Daftar Pustaka}

[1] Xia, K., Lee, S., \& Son, H. (2020). Adaptive control for multi-rotor UAVs autonomous ship landing with mission planning. Aerospace Science and Technology, 96, 105549.

[2] Cahyadi, A., Herdjunanto, S., \& Hidayat, R. (2017). Inertial Navigation for Quadrotor Using Kalman Filter with Drift Compensation. International Journal of Electrical \& Computer Engineering (2088-8708), 7(5).

[3] Luo, C., McClean, S. I., Parr, G., Teacy, L., \& De Nardi, R. (2013). UAV position estimation and collision avoidance using the extended Kalman filter. IEEE Transactions on Vehicular Technology, 62(6), 2749-2762.

[4] Ghoddousi-Fard, R., \& Lahaye, F. (2015, October). High latitude ionospheric disturbances: Characterization and effects on GNSS precise point positioning. In 2015 International Association of Institutes of Navigation World Congress (IAIN) (pp. 1-6). IEEE.

[5] Zhang, G., \& Hsu, L. T. (2018). Intelligent GNSS/INS integrated navigation system for a commercial UAV flight control system. Aerospace science and technology, 80, 368380.

[6] D. A. Grejner-Brzezinska, C. K. Toth, T. Moore, J. F. Raquet, M. M. Miller dan A. Kealy. (2016). Multisensor Navigation, dalam Proceedings of the IEEE.

[7] Nez, A., Fradet, L., Marin, F., Monnet, T., \& Lacouture, P. (2018). Identification of noise covariance matrices to improve orientation estimation by Kalman filter. Sensors, 18(10), 3490 .

[8] Mudarris, M., \& Zain, S. G. (2020). Implementasi Sensor Inertial Meansurenment Unit (IMU) untuk Monitoring Perilaku Roket. AVITEC, 2(1), 55-64.

[9] Hassanalian, M., Rice, D., \& Abdelkefi, A. (2018). Evolution of space drones for planetary exploration: A review. Progress in Aerospace Sciences, 97, 61-105.

[10] Canciani, A., \& Raquet, J. (2017). Airborne magnetic anomaly navigation. IEEE Transactions on Aerospace and Electronic Systems, 53(1), 67-80.

[11] Rhudy, M. B., Salguero, R. A., \& Holappa, K. (2017). A kalman filtering tutorial for undergraduate students. International Journal of Computer Science \& Engineering Survey, 8(1), 1-9.

[12] Widodo, R. B., \& Wada, C. (2016). Attitude estimation using kalman filtering: external acceleration compensation considerations. Journal of Sensors, 2016.

[13] Bijjahalli, S., Sabatini, R., \& Gardi, A. (2020). Advances in intelligent and autonomous navigation systems for small UAS. Progress in Aerospace Sciences, 115, 100617.

[14] Lasmadi, L., Kurniawan, F., \& Pamungkas, M. I. (2021). Estimasi Sudut Rotasi Benda Kaku Berbasis IMU Menggunakan Kalman Filter. AVITEC, 3(1), 57-68.

[15] Prilian, T., Rusmana, I., \& Handayani, T. (2021). Kursi Roda Elektrik dengan Kendali Gestur Kepala. AVITEC, 3(1), 29-42. 
[16] Tuck, K. (2007). Tilt sensing using linear accelerometers. Freescale semiconductor application note AN3107.

[17] Rafiq, M., Kurniawan, F., \& Purnami, N. A. (2021). Koreksi Sudut Attitude Dan Heading Quadrotor Dengan Perubahan Matriks Kovarian Derau Pengukuran Kalman Filter. SITEKIN: Jurnal Sains, Teknologi dan Industri, 18(2), 251-260

[18] Wicaksono, M. A. R., Kurniawan, F., \& Lasmadi, L. (2020). Kalman Filter untuk Mengurangi Derau Sensor Accelerometer pada IMU Guna Estimasi Jarak. AVITEC, 2(2), 145-160. 